Article

\title{
Applying Talent Quality-Management System (TTQS) to Enhance Information Literacy, Learning Motivation, and Computational Thinking Competency of Nursing Undergraduates
}

\author{
Pei-Jung Wu, Hsing-Yu Hou *(1) and Cheng-Chih Huang
}

Citation: Wu, P.-J.; Hou, H.-Y.; Huang, C.-C. Applying Talent Quality-Management System (TTQS) to Enhance Information Literacy, Learning Motivation, and Computational Thinking Competency of Nursing Undergraduates. Sustainability 2021, 13, 6528. https:// doi.org/10.3390/su13126528

Academic Editors: Sara Lumbreras, Hans-Ferdinand Angel and Lluis Oviedo

Received: 30 April 2021

Accepted: 4 June 2021

Published: 8 June 2021

Publisher's Note: MDPI stays neutral with regard to jurisdictional claims in published maps and institutional affiliations.

Copyright: (c) 2021 by the authors. Licensee MDPI, Basel, Switzerland. This article is an open access article distributed under the terms and conditions of the Creative Commons Attribution (CC BY) license (https:/ / creativecommons.org/licenses/by/ $4.0 /)$.
Center for General Education, National Taichung University of Science and Technology, Taichung 40401, Taiwan; pjwu@nutc.edu.tw (P.-J.W.); jimhuang@nutc.edu.tw (C.-C.H.)

* Correspondence: hsingyuhou@gm.nutc.edu.tw

\begin{abstract}
In Taiwan, the Ministry of Education started promoting computational thinking (CT) and design skills in the programming curriculum in 2018 at all universities. CT, which has been widely discussed in the field of education, is the ability to solve problems that use computer science concepts. For students in non-information technology fields, such as nursing students, a curriculum that integrates nursing education and information literacy can bolster evidence-based practice, enhance professional development, and encourage lifelong learning. However, the programming courses were difficult for non-information learners to apprehend, given their lack of knowledge in programming, and had a low attrition rate. Therefore, it is necessary to establish a sustainable management system in the learning process. It is also important to support the interest and confidence of the nursing learner in the programming curriculum. In this study, a programming course for nursing students was completed. A talent quality-management system (TTQS) for this programming course was built and implemented. A technology acceptance model and learning attitude questionnaires were administered to investigate learners' learning motivation and information literacy. Two nursing classes with 74 freshmen participated in the curriculum in the second semester of the 2020 academic year. The results showed that TTQS, which supports teachers in adjusting pedagogy in a timely manner, can enhance learners' motivation and performance. In this programming course, nursing students can learn CT and information concepts and improve their learning motivation through the design of learner-centred and collaborative learning.
\end{abstract}

Keywords: collaborative learning; computational thinking; information literacy; learning attitude; talent quality-management system; technology acceptance model

\section{Introduction}

In this digital age, programming has become a basic literacy skill. Furthermore, it is important for people to understand the digital technology they encounter and be able to work with it. Therefore, learning programming and coding has become a necessary trend in college education. In Taiwan, the Ministry of Education (MOE) has started promoting computational thinking (CT) and design skills in the curriculum of programming since 2018 in all universities. CT, which has been widely discussed in the field of education, is the ability to solve problems that use computer science concepts [1].

Recently, some researchers have promoted information competency training in nursing education [2] and integrated the concept of programming into the curriculum to enhance students' awareness of electronic documentation and learning on the simulation surface [3]. According to the MOE policy in Taiwan, all students at universities have programming courses, even if they are students of computer science. For students in the non-information technology field, such as nursing students, a curriculum that integrates nursing education 
and information literacy can bolster evidence-based practice, enhance professional development, and encourage lifelong learning [4]. However, some studies have claimed that the programming courses were difficult to apprehend for non-information learners, given their lack of knowledge of programming, and had a low attrition rate $[5,6]$. Therefore, it is crucial to support the interest of nursing learners through the programming curriculum and boost their confidence. Based on human factors associated with learning motivation, factors such as sustainable teaching and learning design positively influenced the students outcomes in multiple fields of study [7-9]. Because most pedagogies follow teacher-centred designs, students' performances are evaluated based on the teaching side alone; however, a good pedagogy improves learning motivation in students (learner's side). Therefore, it is crucial to consider developing a sustainable management system during the curriculum design phase, which provides quality talent training.

Some scholars have found that mobile information technology, such as smartphones, can provide instant access to evidence basic information in clinical nursing education [10-12]. Moreover, the literature shows that the technology acceptance model (TAM) is suitable for measuring information system acceptance because of its adaptability, simplicity, and soundness [13]. Furthermore, learning attitude (LA) of the information tool and TAM were reported to have a positive effect [14,15]. In addition, visual programming technologies have proven to help learners improve their basic programming skills. Studies have found that the App Inventor application can improve users' interest and creativity and enhance their computational thinking skills [16,17]. App Inventor was introduced in the programming curriculum for mobile learning in nursing education to train students in foundational information literacy and CT competency. The technology acceptance model (TAM) and learning attitude (LA) questionnaires were administered to investigate the learner's learning motivation and information literacy in programming.

In this study, a programming course for nursing students was implemented. The advantages of applying Talent Management strategies in healthcare institutions are beneficial to the organization's sustainable development and the talented staff [18]. A talent qualitymanagement system (TTQS) [19] for this programming course was built and implemented to design the curriculum and explore the effect of student feedback on information literacy, learning motivation, and CT competency. Furthermore, it offered learners an option to revise the design of the programming curriculum immediately.

This study aimed to set up a sustainable TTQS and to explore the programming learning motivation and attitude in nursing education from a learner-centred approach. Simultaneously, the development of digital skills among undergraduate nursing students was evaluated on the basis of the CT concept. Furthermore, App Inventor was used to train the nursing students on electronic document simulation and design related to their information literacy. According to the analysis of the results, integrating the concepts of $\mathrm{CT}$ and healthcare apps into this programming course can not only help nursing students have the motivation and capability to mediate and solve problems but also satisfy the educational objective of nursing education.

\section{Literature Review}

\subsection{Materials for Preparing the Programming Course}

\subsubsection{TTQS}

TTQS focuses on the quality of service. Based on ISO10015, the European vocational training policy, the British IIP talent investment plan, and the Australian active vocational training policy, the Ministry of Labour in Taiwan developed TTQS in 2005 and provided a follow-up report on the effectiveness of TTQS in 2012. This system involves a plan, design, do, review, and outcome with 18 items for evaluation to ensure that enterprises provide reliable and appropriate training to their employees. According to some studies, TTQS can effectively enhance institutional human capital and strengthen its competitiveness internationally [19-21]. In the programming design curriculum, teaching quality should be 
guided by a stable system. Therefore, TTQS will be applied to the process management of this programming course in this study.

\subsubsection{App Inventor}

Game-based learning, problem-based learning, and visual programming proved to be useful technologies that helped learners perform better in basic programming courses. App Inventor for mobile learning was built for students without programming skills. This is a programming tool for Android apps with graphical building blocks, which is suitable for beginners [22]. It is also a visual programming environment featuring an interface very similar to that of Scratch, but it is oriented toward the intuitive development of fully functional applications for mobile phones and tablets with text and images. Because App Inventor has a low entry barrier and allows novices to write, debug, and run programs with confidence and interest [22,23], we used this software to teach nursing students while avoiding frustration in the beginning stage of learning programming.

\subsubsection{Technology Acceptance Model (TAM)}

With the goal of enhancing the digital literacy of students, educational systems have recently begun incorporating digital skills into course curricula and student evaluations [24]. This developmental change necessitates the inclusion of technology in teaching and learning contexts [25]. Integrating technology is a complex process in terms of educational change; however, teachers include technology in their teaching as a tool to facilitate learning or as a means of formative assessment [26]. Research shows that the extent of technological applications in schools is still extremely diverse [27] and needs further investigation. The main question is the extent to which teachers can integrate technology into teaching and learning activities.

In the past, a large body of literature has dealt with factors associated with this inclusion by focusing on teachers' adoption of technology [28]. The model that dominates the research landscape is the TAM. TAM was developed by Dr. Davis to model how users accept and use a technology. The external variables of TAM are behavioural intentions to use (BI) and attitude toward using (ATU), and the internal beliefs are perceived usefulness (PU) and perceived ease of use (PEU). PEU and PU refer to the extent to which an individual believes that using technology is 'free from difficulty or great effort' (PEU) and that using technology will improve their job or task performance (PU) [29]. Therefore, PEU represents the effort of an individual to use technology, which is closely related to their competence beliefs [30]. TAM theorises that PU and PEU are affected by external variables. Thus, PU and PEU mediate the effect of external variables on the user's attitude and BI, and therefore, use of the actual system. Several researchers have provided substantial examinations and analyses of TAM [10,31,32]. In this study, we focus on PU and PEU, which are considered key variables that directly or indirectly explain the outcomes [10].

\subsubsection{Learning Attitude (LA)}

Learning attitude (LA) has a remarkable influence on learning effects [33-35]. Some scholars have reported the positive effects of students' learning motivation and learning attitudes on their learning achievements [36-38]. Hwang et al. developed a measure that was used to derive the LA questionnaire for assessing nursing students in this course and evaluate their effect [39]. The modified TAM and LA questionnaires are listed in the Appendices A and B.

\subsection{Design of the Programming Course}

\subsubsection{TTQS in This Study}

In the present study, TTQS was used to explore the effect of information literacy and $\mathrm{CT}$ competency in a programming curriculum in nursing education. A diagnosis was made to investigate the relationship during one semester in the experimental classes. The main objective of the present study was to set up a quality-management checklist from the 
TTQS components—-plan, design, do, review, and outcome—-to enhance the information literacy and CT competency of undergraduate students in the nursing department. We used management indicators in the App Inventor training as outlined by the MOE rules. The research structure is presented in Table 1.

Table 1. Talent quality-management system in this study.

\begin{tabular}{|c|c|c|}
\hline Aspects & Emphatic Facets & Relative Work in This Study \\
\hline Plan & $\begin{array}{l}\text { Focus on relativity and the practice of } \\
\text { training plan and institution's goal. }\end{array}$ & $\begin{array}{l}\text { - Accord with goals from MOE in Taiwan and trends of } \\
\text { digital age. } \\
\text { - } \quad \text { Define KPI of this programming course. } \\
\text { - Enhance nursing students' information literacy and CT } \\
\text { competency. }\end{array}$ \\
\hline Design & $\begin{array}{l}\text { Focus on the design of training system } \\
\text { (including the involvement of the } \\
\text { beneficial party, standard of course } \\
\text { selections, purchase standard). }\end{array}$ & $\begin{array}{l}\text { Design a suitable course for nursing students, such as } \\
\text { - } \quad \text { Integrate CT skills into the training schedule including } \\
\text { CT decomposition, pattern recognition, abstraction, } \\
\text { and algorithm design. } \\
\text { - Set up monitoring parameters from TAM and LA } \\
\text { questionnaire. }\end{array}$ \\
\hline Do & $\begin{array}{l}\text { Emphasize the process of training, } \\
\text { records, and the standardization of } \\
\text { management. }\end{array}$ & $\begin{array}{l}\text { - Implement the proposed programming course in } \\
\text { nursing education. } \\
\text { - } \quad \text { Prepare teaching materials. } \\
\text { - } \quad \text { POP of training schedule and teachers based on CT. } \\
\text { - } \quad \text { Questionnaire surveys for tracking the interest and } \\
\text { confidence of students. }\end{array}$ \\
\hline Review & $\begin{array}{l}\text { Focus on periodical analysis, monitoring, } \\
\text { and reaction to accidents. }\end{array}$ & $\begin{array}{l}\text { - Results of TAM survey* and LA survey *. } \\
\text { - Adjust the teaching pedagogy for final reports } \\
\text { (collaborative learning). }\end{array}$ \\
\hline Outcome & $\begin{array}{l}\text { Focus on layers, completeness, and } \\
\text { sustained improvement of training } \\
\text { evaluation. }\end{array}$ & $\begin{array}{ll}\text { - } & \text { Final report scores. } \\
\text { - } & \text { E-learning record. } \\
\text { - } & \text { CT performance. } \\
\text { - } & \text { Satisfaction. }\end{array}$ \\
\hline
\end{tabular}

Abbreviations: TAM—-technology acceptance model; LA—learning attitude; CT—computational thinking; KPI—key performance indicators; MOE-Ministry of Education. Note: The star $\left(^{*}\right)$ implies the alerting of the curriculum to the nursing department for the teacher.

\subsubsection{CT Training with App Inventor}

Because the curriculum is designed in the nursing department, the teaching objective is oriented toward solving problems with smart tools and enhancing information literacy and CT competency in nursing education. We first applied the CT concept in App Inventor through a healthcare simulation of body mass index (BMI) evaluation. Body mass index is a reliable and common indicator to help people determine their body composition. In this lesson, nursing students created a program by using App Inventor to calculate their personal BMI and nutritional status by inputting their weight and height. This program can be divided into two parts. One is the main function which can define parameters, including input height, input weight, and output BMI, and calculate BMI values. The BMI formula is shown in Equation (1). The second is a sub-function which can classify nutritional status based on different BMI values. To classify nutritional status, students need to recognise the pattern of this classification. In this section, the classification of BMI categories for Asia [40] is the basis of this classification. Then, students can obtain the abstraction and design algorithm by generating the above information, the calculated BMI values, and the 
classification of BMI categories included. The results of the completed app interface and program are shown in Figure 1.

$$
\text { output_BMI }=\frac{\text { input_weight }}{\text { Input_height }}
$$
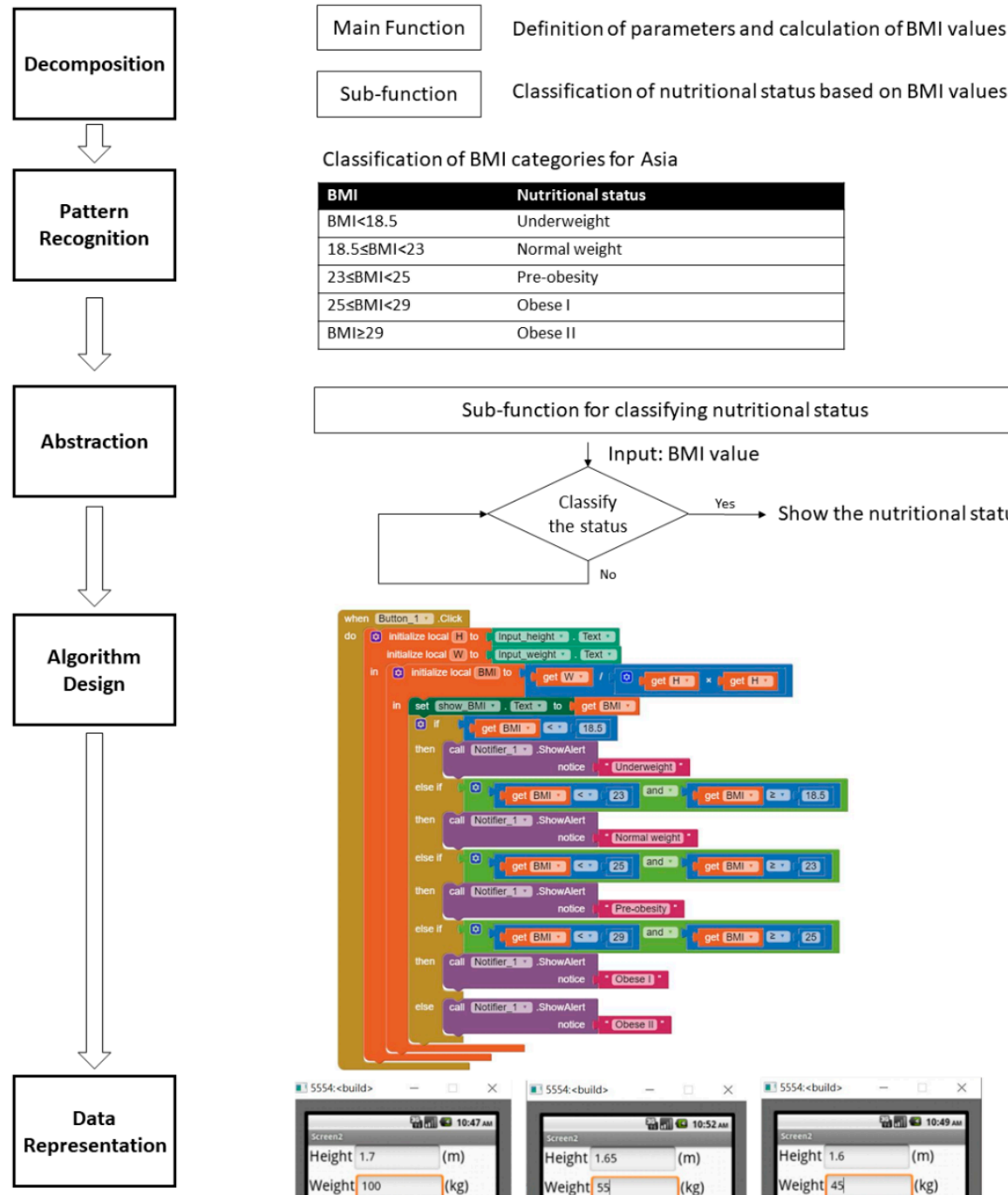

Classification of BMI categories for Asia

\begin{tabular}{|ll|}
\hline BMI & Nutritional status \\
\hline BMI $<18.5$ & Underweight \\
\hline $18.5 \leq B M \mid<23$ & Normal weight \\
\hline $23 \leq B M \mid<25$ & Pre-obesity \\
\hline $25 \leq B M \mid<29$ & Obese I \\
\hline BMI 29 & Obese II \\
\hline
\end{tabular}
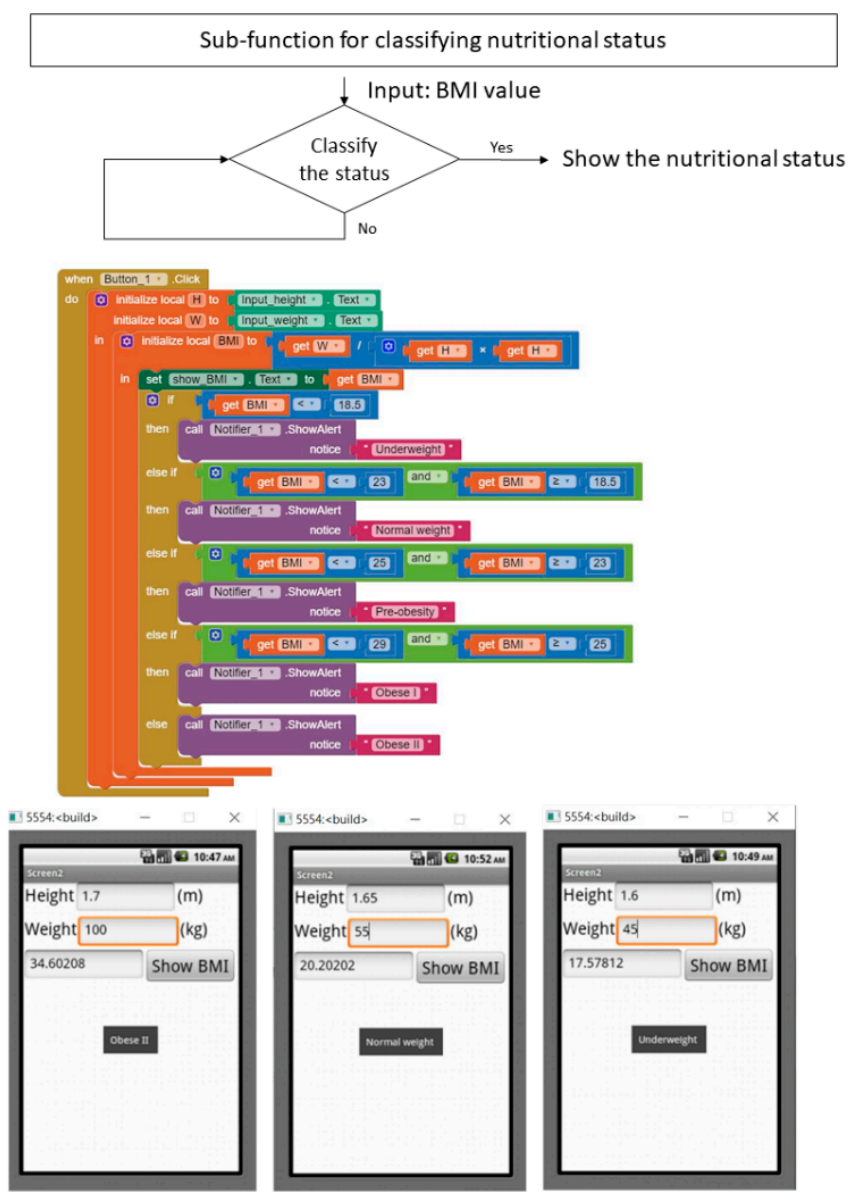

Figure 1. One lesson of computational thinking in this curriculum. BMI—body mass index.

\subsubsection{Collaborative Learning}

There have been several innovative instructional approaches in current educational settings in the past few decades. Among them, collaborative learning (CL) plays a very important role [41]. In the past few decades, the focus of student learning has shifted from individual learning to CL [42]. Collaborative learning can be defined as a teaching approach in which students are expected to depend on and be accountable for their own and each other's learning [43]. This often leads to deep information processing and stimulating interactions in valuable learning activities [42]. 
Researchers propose that the use of CL in the classroom positively impacts both the (meta) cognitive performance, social behaviour, and affective perceptions of students [44-46]. Researchers have also shown that working collaboratively induces many beneficial outcomes, such as increased learning and more positive student attitudes toward school, leading to motivation in computer programming education [47-51]. Keeler and Steinhorst also observed that a higher percentage of students successfully completed courses when the classes used CL methods [49]. This finding holds true for all students, regardless of demographic differences, such as sex, race, or precollege academic ability [50]. In this study, we used collaborative learning to adjust teaching pedagogy when we determined that the students' progress in the course was not satisfactory. We let the class with lower intentions discuss programming questions using collaborative learning. The class with higher intentions employed direct thinking individually.

\section{Methodology}

According to the five steps of the TTQS (i.e., plan, design, do, review, and outcome), action research was applied and designed to detect the learners' behaviour and the effect of pedagogy modification of the instructor. Action research has been shown to be able to afford localized solutions and is a systematic approach toward the investigation of a particular event or experience that causes some form of change [52-54]. Therefore, this sustainable management system was utilized to detect the information literacy, learning motivation, and CT competency of nursing undergraduates in this study.

\subsection{Samples and Procedure}

The curriculum is designed by the nursing department in the case university, and two classes were introduced, with a total of 80 students enrolled in the programming curriculum for the second semester of the 2020 academic year. From the 80 students invited to participate in the experiment by the researcher, 74 freshmen (Class A: $n=39$; Class B: $\mathrm{n}=35$ ) agreed to answer the TAM and LA questionnaires and were used as the sampling pool. In the beginning stage of the plan in TTQS, the goal of the programming curriculum was to develop information literacy and CT competency of undergraduate students in the nursing department in the case university. The instructor added a declaration at the beginning of the survey, stating that the curriculum will only be used by academic institutions, and not for business purposes. All participants were unaware of the hypotheses, and the questionnaire did not include the participants' personal details, with their names kept anonymous. In addition, two questionnaires were related to the evaluation of teaching pedagogies. Therefore, the ethical procedure was followed and matched the regulations of exemption from the IRB review in the Ministry of Health and Welfare, Taiwan [55]. All data were also stored securely, with access limited to the researchers.

Regarding the teaching methodology, the teacher taught simple to advanced skills and allowed students to practice step-by-step with visual information software in a computer class. In the first class, the teacher demonstrated each case and described the concept of a $\mathrm{CT}$ foundation using teaching materials. In this programming design curriculum, the teacher arranged the teaching materials from foundation (concept or basic computing) to advanced contents (loop or array) for 18 weeks in the semester. Students answered the TAM and LA questionnaires after completing the mid-term exam (a test of foundational skills). According to the analysed results from the scores of the mid-term exam and TAM and LA questionnaires, the pedagogies in the section on creating the application with App Inventor were adjusted. The class with poor intention scores with App Inventor was rearranged by the teacher to allow cooperation to complete the final report. Finally, we performed data analysis using basic statistical methods and correlation analysis through an e-learning record and final report scores. The experimental procedure is illustrated in Figure 2. 


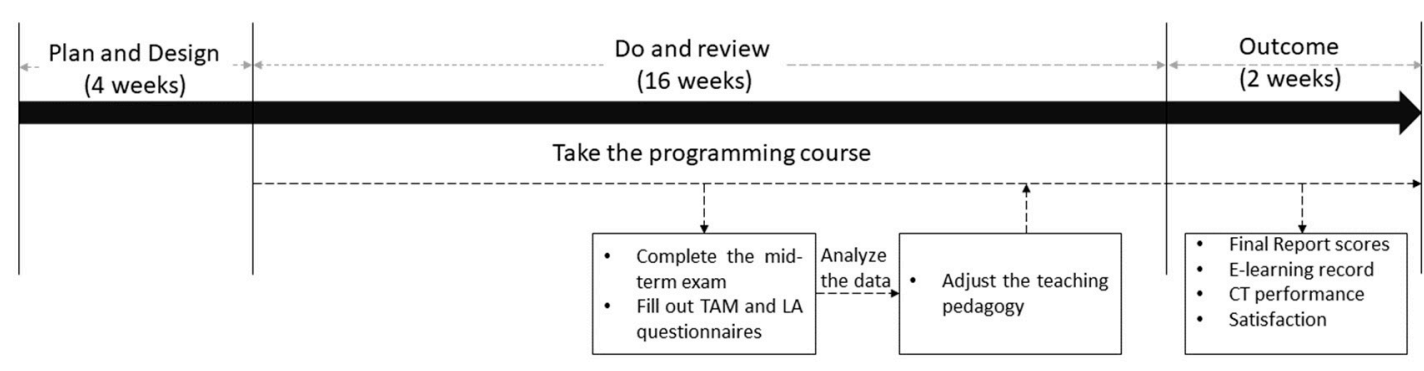

Figure 2. Experimental procedure of this study.

\subsection{TAM and LA Questionnaires}

For the TAM questionnaire (Appendix A), we measured the variables PU, PEU, ATU, and BI. The PU items included the following: 'Using computational thinking in my job will enable me to accomplish tasks more quickly', 'Using computational thinking will improve my job performance', 'Using computational thinking in my job will increase my productivity', 'Using computational thinking will enhance my effectiveness on the job', 'Using computational thinking will make it easier to do my job', and 'I'll find computational thinking useful in my job'. The PEU variable included the following items: 'Learning to operate computational thinking will be easy for me', 'I will find it easy to use computational thinking to do what I want to do', 'My interaction with computational thinking will be clear and understandable', 'It will be easy for me to become skilful at using computational thinking', and 'I will find computational thinking easy to use'. For the measuring the ATU variable, the following statement was used: 'I accept the use of computational thinking in learning activities. Similarly, only one item was used to measure BI: 'I will continue to incorporate computational thinking into my learning activities.' A total of 14 items were used in the questionnaire.

The items under learning attitudes (Appendix B) included the following items: 'I think learning computational thinking is interesting and valuable', 'I would like to learn more and observe more in the programming course', 'It is worth learning those things about computational thinking', 'It is important for me to learn the programming course well', 'It is important to know the computational thinking knowledge related to our living environment', 'I will actively search for more information and learn about computational thinking', and 'It is important for everyone to take the programming course'. A total of 7 items were used in this questionnaire.

The items listed under TAM and LA were selected from the questionnaire of the researcher $[29,39]$. Two questionnaires were found to be reliable from the results of scholars (Cronbach alpha values were higher than 0.90 in TAM and 0.79 in LA) and were used in the survey. Both questionnaires followed the Likert scales scoring system. Students answered using a five-point scale, where points 5 to 1 , in order, denoted "strongly agree", "agree", "neutral ", "disagree" and "strongly disagree", respectively.

\subsection{CT Performance and E-learning Record}

To assist learners in improving their learning achievements in such a situated learning scenario, researchers provided several suggestions for instructional design, including the selection of situations that would afford specific knowledge to be learned [56] and the development of effective mobile learning strategies [57]. Therefore, the score of the final report was discussed to understand the effect of learning computational thinking with App Inventor.

Mahajan et al. [58] researched the usability and effectiveness of e-content by analysing web logs. After the mid-term evaluation, the teacher taught more advanced contents such as loop and array concepts for designing interesting and useful apps and added e-learning records to detect the learners' behaviour. Through the learning record in the e-learning platform, researchers were able to collect the number of logins, reading pages, time, and 
frequencies in the learning process to explore the results after teaching the BMI example during the last four sessions before the final evaluation. From the data, we can compare the differences between individual work and group cooperation.

\section{Results}

\subsection{The Basis of TTQS Review}

In the TAM and LA analyses regarding computational thinking with App Inventor (shown in Tables 2 and 3), some items had class means below 3.7. Some learners faced difficulty learning computational thinking and poor learning attitude, as demonstrated by items 7, 11, and 14 under PEU and item 6 in LA, respectively. In Class B, the averages of PU, PEU, BI, and LA were all lower than they were in class A. Therefore, the teacher in Class $\mathrm{B}$ adjusted the pedagogy by creating two-person groups and letting them cooperate to finish the final report.

Table 2. Results of the technology acceptance model questionnaire. Bold items indicate mean below 3.7.

\begin{tabular}{llll}
\hline & \multicolumn{1}{c}{ Items } & Class A & Class B \\
\hline Perceived usefulness (PU) & & \\
$\begin{array}{l}\text { 1. } \quad \text { Using computational thinking in my job will enable me to accomplish } \\
\text { tasks more quickly. }\end{array}$ & $4.26 \pm 0.75$ & $4.20 \pm 0.76$ \\
2. $\quad$ Using computational thinking will improve my job performance. & $4.33 \pm 0.74$ & $4.06 \pm 0.80$ \\
3. $\quad$ Using computational thinking in my job will increase my productivity. & $4.28 \pm 0.83$ & $4.29 \pm 0.79$ \\
4. $\quad$ Using computational thinking will enhance my effectiveness on the job. & $4.33 \pm 0.77$ & $4.17 \pm 0.79$ \\
5. $\quad$ Using computational thinking will make it easier to do my job. & $4.28 \pm 0.79$ & $3.97 \pm 0.86$ \\
6. $\quad$ I will find computational thinking useful in my job. & $4.18 \pm 0.85$ & $4.28 \pm 0.79$ & $4.06 \pm 0.97$ \\
Average &
\end{tabular}

\section{Perceived ease of use (PEU)}

7. Learning to operate computational thinking will be easy for me.

$\begin{array}{ll}3.54 \pm 1.14 & 3.57 \pm 1.09 \\ 4.05 \pm 0.83 & 3.71 \pm 1.02 \\ 4.00 \pm 0.86 & 3.91 \pm 0.95 \\ 4.23 \pm 0.71 & 4.09 \pm 0.89 \\ 3.62 \pm 1.07 & 3.46 \pm 1.07 \\ 3.92 \pm 0.90 & 3.77 \pm 0.88 \\ 3.89 \pm 0.92 & 3.75 \pm 0.98\end{array}$

Average

$4.09 \pm 0.82$

13. I accept the use of computational thinking in learning activities.

$4.05 \pm 0.83$

\section{Behavioural intentions (BI)}

14. I will continue to incorporate computational thinking into my learning activities. 
Table 3. Results of learning attitudes questionnaire. Bold items indicate mean below 3.7.

\begin{tabular}{|c|c|c|c|}
\hline & Items & Class A & Class B \\
\hline \multicolumn{4}{|c|}{ Learning Attitudes (LA) } \\
\hline 1. & I think learning computational thinking is interesting and valuable. & $4.13 \pm 0.86$ & $4.14 \pm 0.85$ \\
\hline 2. & I would like to learn more and observe more in the programming course. & $4.18 \pm 0.76$ & $4.06 \pm 0.76$ \\
\hline 3. & It is worth learning those things about computational thinking. & $4.36 \pm 0.74$ & $4.11 \pm 0.80$ \\
\hline 4 . & It is important for me to learn the programming course well. & $4.15 \pm 0.84$ & $4.06 \pm 0.87$ \\
\hline 5. & $\begin{array}{l}\text { It is important to know the computational thinking knowledge related to } \\
\text { our living environment. }\end{array}$ & $3.90 \pm 0.85$ & $3.91 \pm 0.98$ \\
\hline 6. & $\begin{array}{l}\text { I will actively search for more information and learn about } \\
\text { computational thinking. }\end{array}$ & $3.69 \pm 0.98$ & $3.63 \pm 1.09$ \\
\hline 7. & It is important for everyone to take the programming course. & $4.10 \pm 0.82$ & $4.00 \pm 0.87$ \\
\hline \multicolumn{2}{|c|}{ Average } & $4.07 \pm 0.84$ & $3.99 \pm 0.89$ \\
\hline
\end{tabular}

In the correlation analysis, the items under LA, PU, and PEU were all positively related to attitude and behaviour for computational thinking with App Inventor, as shown in Table 4. High correlation values were observed between the LA and TAM in this study.

Table 4. Correlation between the parameters of the learning attitude and technology acceptance models.

\begin{tabular}{cccccc}
\hline & LA & PU & PEU & ATU & BI \\
\hline LA & 1 & & & & \\
PU & $0.738^{* *}$ & 1 & & & \\
PEU & $0.647^{* *}$ & $0.808^{* *}$ & 1 & 1 & \\
ATU & $0.687^{* *}$ & $0.878^{* *}$ & $0.801^{* *}$ & $0.788^{* *}$ & 1 \\
BI & $0.644^{* *}$ & $0.761^{* *}$ & $0.797^{* *}$ &
\end{tabular}

Note: ${ }^{* *} p$-value is smaller than 0.01 . Abbreviations: LA-learning attitude; PU—perceived usefulness; PEUperceived ease of use; ATU—attitude towards using; BI—behavioural intention.

\subsection{Outcomes of TTQS}

Based on the TAM and LA analysis, it was found that the students in Class B had lower intentions in this programming curriculum. Therefore, we used cooperative learning to decrease students' fear.

From the e-learning record, the average login frequency of this semester was 108.33 in Class A and 137.54 in Class B. We also found that the login frequency during the total semester was significantly higher in Class B $(t$-test, $p=0.004)$. In addition, Table 5 shows students' e-learning records while they studied four chapters after the teaching pedagogy was adjusted. The value of reading frequencies is similar, but the reading time of the last four chapters increased in Class B after the pedagogy change.

Table 5. E-learning records of each chapter after adjusting the teaching pedagogy.

\begin{tabular}{lcccc}
\hline \multicolumn{1}{c}{ Chapter } & \multicolumn{2}{c}{ Class A } & \multicolumn{2}{c}{ Class B } \\
& Frequencies & Time & Frequencies & Time \\
\hline Ch 6 Logical judgment (BMI example) & 105 & $29: 45: 21$ & 77 & $30: 04: 09$ \\
Ch 7 Logical judgment and loop & 73 & $22: 33: 47$ & 82 & $23: 19: 21$ \\
(Ultimate password game) & 102 & $38: 13: 18$ & 86 & $36: 13: 32$ \\
Ch 8 Array (Rock-paper-scissors game) & 183 & $41: 01: 04$ & 213 & $56: 16: 27$ \\
Ch 9 Open Database & $\mathbf{1 1 6}$ & $\mathbf{3 2 : 5 1 : 4 5}$ & $\mathbf{1 1 5}$ & $\mathbf{3 6 : 2 8 : 2 2}$ \\
(Weather monitoring example) & & & & \\
Average & & &
\end{tabular}


The scores related to this programming curriculum are shown in Table 6. The scores of the mid-term exam in both classes were similar. After the review and pedagogy change, the final scores of class B (mean score $=79.18$ ) were slightly better than those of class A (mean score $=78.45$ ). In addition, both average teaching evaluation scores of satisfaction (teaching attitude, teaching pedagogy, teaching material, and evaluation) were higher than 4.5 , in both Class A and Class B.

Table 6. Related scores from this proposed curriculum.

\begin{tabular}{ccc}
\hline & Class A & Class B \\
\hline Mid-exam (1-100) & $97.19 \pm 6.42$ & $96.74 \pm 10.25$ \\
Final report (1-100) & $78.45 \pm 6.69$ & $79.18 \pm 7.32$ \\
Satisfaction (1-5) & 4.72 & 4.58 \\
\hline
\end{tabular}

After the BMI training lesson in the nursing department with App Inventor, the teacher allowed the students to extend the CT function to other health care issues and design an app for interesting games. Figure 3 shows one example of a final report, including decomposition, pattern recognition, abstraction, and algorithm design. It shows that the students have CT competency and information literacy after training with App Inventor in nursing education. 
Brief Introduction of this applied healthcare app:

An applied healthcare app was completed in this report. The users can enter their gender, height, and everyday workload. Then the app will show the ideal weight of the user and recommended daily calorie intake.

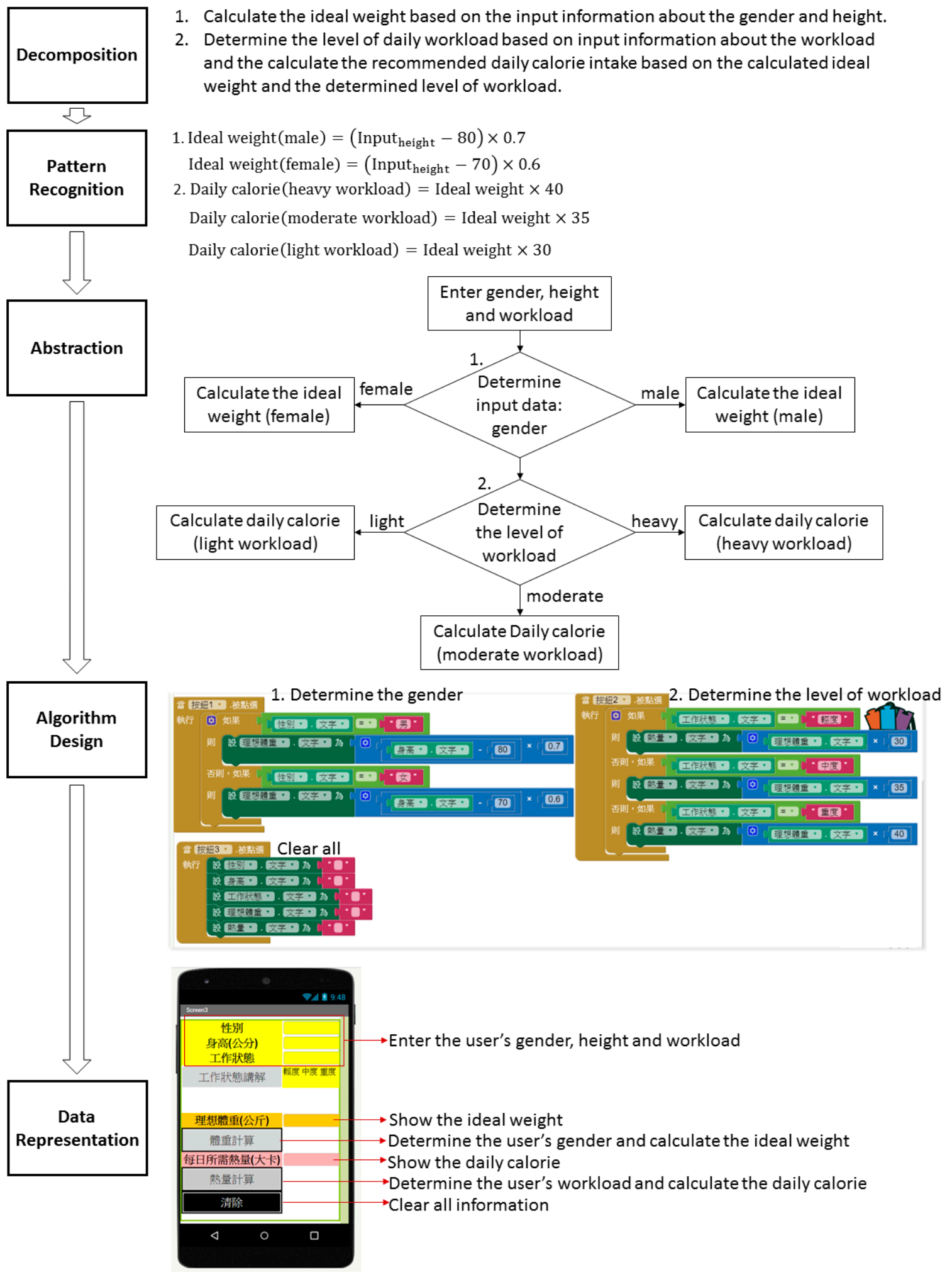

Figure 3. Demonstration of one example in the students' final report. 


\section{Discussion}

5.1. TAM and LA

For a teacher in programming teaching or students in programming learning, the standard operational process is very important to provide good training and improve training quality. This study used the TTQS to manage the programming curriculum for nursing students. The analysis results from the TAM and LA questionnaires mid-semester were considered as the review items. Both questionnaires are reliable to understand the motivation and attitude of learners. Based on them, we found that PU, PEU, BI, and LA in Class B were lower than in Class A. Moreover, we found that all parameters in this review-LA, PU, PEU, ATU, and BI-are positively related to each other. This indicates that the relationship between students' attitudes and behaviours in this study had a high positive correlation [11,12]. Hou et al. [59] also applied the TAM to check the learning performance of undergraduates from non-information technology fields. The results confirmed that TAM and LA successfully predicted the user behaviour and attitude of participants using new information technologies. In addition, the two surveys aided in enhancing the implementation of quality assurance mechanisms in order to improve the efficiency and effectiveness of the educational process. Thus, the results of this programming curriculum are consistent with the previous work.

\subsection{TTQS and Cooperative Learning}

Based on the mid-term results, the teacher adjusted the pedagogy to help students with lower intention on the learner-centred side. After the adjustment in pedagogy, we found that the outcomes of TTQS, such as scores of the final reports, CT performance, and satisfaction in both classes were similar. In other words, the TTQS comprises a five-step training management cycle, which supports the teacher in adjusting the pedagogy in real time or allowing the manager to control the operational process immediately, and can enhance learners' motivation and performance smoothly $[7,60,61]$. Numerous studies have shown that TTQS plays a vital role for quality talent training in a sustainable management system. In addition, cooperative learning was used to help students with lower intentions to improve their CT performance at the end of the semester. Students could read the teaching materials on the e-learning platform and discuss them with their group members. The reading time of the last four chapters in Class B, which had a lower intention in the programming course, was more than that of Class A. This can explain why cooperative learning can be promoted to enhance beneficial outcomes [38,39,62]. The use of cooperative learning in the classroom has been proposed to positively impact the cognitive performance, social behaviour, and affective perceptions of students. Hence, pedagogy is useful for the instructor to modify the alerting at the review stage.

\subsection{CT Using App Inventor}

The programming curriculum for students without an information technology background started in 2018 in higher education in Taiwan. According to the learning objectives of nursing education [63], having the capability to mediate and solve problems is an important goal for nursing students. In addition, many scholars have proved the importance and advantage of information literacy in nursing education in terms of communication skills [64-66]. Therefore, our team applied CT concepts with App Inventor to the design of this programming curriculum to help nursing students learn programming and information literacy easily. Scratch and Tableau were also applied as CT concepts to check the learning performance of undergraduates from non-information technology fields [59]. The participants in a previous or this study could use the CT process through abstraction, algorithm design, decomposition, data analysis, and pattern recognition to set up an information system. This proposed programming course was the preliminary phase in providing opportunities to enable non-information technology students to engage in CT competency. The achievement for the students was to successfully create innovative application programming and simulation surface. The benefit for the nursing undergradu- 
ates was that after learning the CT concepts with App Inventor, they could enhance their professional development between CT competency and information literacy.

\subsection{Sustainable Information System Development in Nursing Education}

With the advancement of mobile technology, people find that innovative mobile phonebased tools may be superior to conventional tools in large-scale setups because of their feasibility and cost-effectiveness [67]. In this programming course, nursing students learned not only CT concepts but also the design of healthcare apps to enhance the opportunity of 'paperlessness' in workplaces. By integrating CT concepts, a design framework [68], healthcare information, and user needs, students can explore, design, and evaluate a useful and feasible app. This ability may be an interdisciplinary and important skill for nursing students when they start working. Wang et al. [69] proposed that user interface feature lists are created and user interface design is prioritised by the cognitive walkthrough of doctors and nurses, providing a good foundation for application development and promotion in hospitals. Therefore, helping nursing students learn CT concepts and design apps efficiently may become a trend as a feasible and efficient solution that fits in clinical practices can be designed and accomplished by doctors, nurses, and technologists in this digital age. In summary, the healthcare topics with App Inventor could offer a user-friendly interface and facilitate health information around us easily. This is a win-win situation between designers and users.

\subsection{Study Limitations}

This study entailed action research, not fundamental research. The purpose of action research does not emphasize the development of theory and the universal applicability of research results, but the design of research that is aimed at the characteristics of the problem in a specific time, place, and situation. Therefore, the samples in this research were specific research subjects (i.e., the nursing students at the university), not random samples from the mother population. Considering that the proposed programming course was designed for the nursing students in the case university, it may not be suitable for students from other fields of study. However, it can be promoted to other departments and universities, while semesters could be extended to evaluate the growth of information competency in advanced research. In addition, the information tool in this study was associated with App Inventor and constituted only one part of interactive software in the learning programming curriculums. For future research, more visual interactive software and game-based information systems can be designed and compared to evaluate the performance of the foundation programming design.

\section{Conclusions}

CT concepts and information literacy play an important role in the digital age. To enhance nursing students' information literacy, learning motivation, and CT competency, this study proposed a mobile programming course using TTQS. TTQS comprises a five-step training management cycle which can support the teacher to adjust pedagogy in a timely manner to enhance students' learning attitude and performance. Cooperative learning was used to help students improve their learning motivation, and with the assistance of e-learning, it contributed to better outcomes at the end of the semester. Moreover, by integrating CT concepts, a design framework, healthcare information, and user needs, students can explore, design, and evaluate a useful and feasible app after they start working. In summary, the app output is a sustainable tool in nursing education to reduce the waste of paper resources, and it is a useful and easy-to-operate information system to assist healthcare industries in the future.

Author Contributions: All authors made significant contributions throughout this piece of research and agreed to submit the manuscript in the current form. P.-J.W. and H.-Y.H. made major contribution in terms of writing, designing questionnaires and analyzing data. C.-C.H. contributed in terms of 
conceptualization, and revising the manuscript. All authors have read and agreed to the published version of the manuscript.

Funding: This research was partially supported by the Ministry of Education, Taiwan, China under the Grant [MOE PGE1090786].

Institutional Review Board Statement: This research is in the exemption from the review of Ethics Committee in Taiwan.

Conflicts of Interest: The authors declare no conflict of interest.

\section{Appendix A Questionnaire Items of TAM}

1. Using computational thinking in my job will enable me to accomplish tasks more quickly.

2. Using computational thinking will improve my job performance.

3. Using computational thinking in my job will increase my productivity.

4. Using computational thinking will enhance my effectiveness on the job.

5. Using computational thinking will make it easier to do my job.

6. I will find computational thinking useful in my job.

7. Learning to operate computational thinking will be easy for me.

8. I will find it easy to use computational thinking to do what I want to do.

9. My interaction with computational thinking will be clear and understandable.

10. I will find computational thinking to be flexible to interact with.

11. It will be easy for me to become skilful at using computational thinking.

12. I will find computational thinking easy to use.

13. I accept the use of computational thinking in learning activities.

14. I will continue to incorporate computational thinking into my learning activities.

\section{Appendix B Questionnaire Items of LA}

1. I think learning computational thinking is interesting and valuable.

2. I would like to learn more and observe more in the programming course.

3. It is worth learning those things about computational thinking.

4. It is important for me to learn the programming course well.

5. It is important to know the computational thinking knowledge related to our living environment.

6. I will actively search for more information and learn about computational thinking.

7. It is important for everyone to take the programming course.

\section{References}

1. Boom, K.-D.; Bower, M.; Arguel, A.; Siemon, J.; Scholkmann, A. Relationship between computational thinking and a measure of intelligence as a general problem-solving ability, ITiCSE. Proceedings 2018, 2018, 206-211.

2. Gonen, A.; Sharon, D.; Lev-Ari, L. Integrating information technology's competencies into academic nursing education-an action study. Cogent Educ. 2016, 3, 1-9. [CrossRef]

3. Kowitlawakul, Y.; Wang, L.; Chan, S.W. Development of the electronic health records for nursing education (EHRNE) software program. Nurse Educ. Today 2013, 33, 1529-1535. [CrossRef] [PubMed]

4. Beck, S.; Blake-Campbell, B.; Mckay, D. Partnership for the advancement of information literacy in a nursing program. Commun. Jr. Coll. Libr. 2012, 18, 3-11. [CrossRef] 
5. Beaubouef, T.; Mason, J. Why the high attrition rate for computer science students: Some thoughts and observations. ACM SIGCSE Bull. 2005, 37, 103-106. [CrossRef]

6. Ma, L.; Ferguson, J.; Roper, M.; Wood, M. Investigating and improving the models of programming concepts held by novice programmers. Comput. Sci. Educ. 2011, 21, 57-80. [CrossRef]

7. Murphy, P.K.; Alexander, P.A. A motivated exploration of motivation terminology. Contemp. Educ. Psychol. 2000, 25, 3-53. [CrossRef]

8. Pintrich, P. Motivation and classroom learning. In Handbook of Psychology: Educational Psychology; Reynolds, W., Miller, G., Eds.; John Wiley \& Sons: Hoboken, NJ, USA, 2003; Volume 7, pp. 103-122.

9. Ryan, R.M.; Deci, E.L. Self-determination theory and the facilitation of intrinsic motivation, social development, and well-being. Am. Psychol. 2000, 55, 68-78. [CrossRef]

10. Marangunić, N.; Granić, A. Technology acceptance model: A literature review from 1986 to 2013. Univers. Access Inf. Soc. 2015, 14, 81-95. [CrossRef]

11. Jayaweera, Y.D.; Gapar, M.; Johar, M.; Perera, S.N. Enabling effective personalized learning: Determinants for knowledge based web information retrieval systems. Int. J. Comput. Appl. 2015, 116, 19-24. [CrossRef]

12. Van De Bogart, W.; Wichadee, S. Exploring students' intention to use LINE for academic purposes based on technology acceptance model. Int. Rev. Res. Open Distrib. Learn. 2015, 16, 65-85. [CrossRef]

13. Beauregard, P.; Arnaert, A.; Ponzoni, N. Nursing students' perceptions of using smartphones in the community practicum: A qualitative study. Nurse Educ. Today 2017, 53, 1-6. [CrossRef]

14. O'Connor, S.; Andrews, T. Implementing mobile information technology in clinical nursing education: How, why, when, where and what happened? Some answers from a review of the literature. BMC Health Serv. Res. 2014, 14, 88. [CrossRef]

15. Raman, J. Mobile technology in nursing education: Where do we go from here? A review of the literature. Nurse Educ. Today 2015, 35, 663-672. [CrossRef]

16. $\mathrm{Wu}, \mathrm{M}$. Computational Thinking Oriented App Inventor Course Construction and Practice; Hangzhou Dianzi University: Hangzhou, China, 2015; Volume 35, pp. 93-97.

17. Guo, S.; Zhou, R.; Deng, C.; Di, C.; Zhou, Q. Instructional research of information technology based on app inventor and computational thinking. CET China Educ. Technol. 2014, 3, 91-96.

18. Mitosis, K.D.; Lamnisos, D.; Talias, M.A. Talent management in healthcare: A systematic qualitative review. Sustainability 2021, 13, 4469. [CrossRef]

19. Chen, F.-S.; Hsu, S.-W.; Hung, M.-C.; Wu, Y.-C. Application of the talent quality-management system to assess training effectiveness of enterprises. Int. J. Organ. Innov. 2016, 8, 84-88.

20. Hsieh, S.-C.; Lin, J.-S.; Hung-Chun, L. Analysis on literature review of competency. Int. Rev. Bus. Econ. 2012, 2, 25-50.

21. Shi, M.F. Application of TTQS to manage the internship quality of vocational school students. Eval. Bimonthly 2012, $37,45-48$.

22. Kowalczyk, R.; Turczyński, Ł.; Żyła, K. Comparison of app Inventor 2 and java in creating personal applications for android on example of a notepad. Adv. Sci. Technol. Res. J. 2016, 10, 247-254. [CrossRef]

23. Papadakis, S.; Orfanakis, V. Comparing novice programing environments for use in secondary education: App Inventor for android vs. Alice. Int. J. Technol. Enhanced Learn. 2018, 10, 44-72. [CrossRef]

24. Buitrago Flórez, F.; Casallas, R.; Hernández, M.; Reyes, A.; Restrepo, S.; Danies, G. Changing a generation's way of thinking: Teaching computational thinking through programming. Rev. Educ. Res. 2017, 87, 834-860. [CrossRef]

25. Siddiq, F.; Scherer, R. The relation between teachers' emphasis on the development of students' digital information and communication skills and computer self-efficacy: The moderating roles of age and gender. Large Scale Assess. Educ. 2016, 4, 1-21. [CrossRef]

26. Shute, V.J.; Rahimi, S. Review of computer-based assessment for learning in elementary and secondary education. J. Comput. Assist. Learn. 2017, 33, 1-19. [CrossRef]

27. Fraillon, J.; Ainley, J.; Schulz, W.; Friedman, T.; Gebhardt, E. Preparing for Life in a Digital Age: The IEA International Computer and Information Literacy Study International Report; Springer: Cham, Switzerland, 2014.

28. Straub, E.T. Understanding technology adoption: Theory and future directions for informal learning. Rev. Educ. Res. 2009, 79, 625-649. [CrossRef]

29. Davis, F.D. Perceived usefulness, perceived ease of use, and user acceptance of information technology. MIS Q. 1989, 13, 319-340. [CrossRef]

30. Scherer, R.; Siddiq, F.; Teo, T. Becoming more specific: Measuring and modeling teachers' perceived usefulness of ICT in the context of teaching and learning. Comput. Educ. 2015, 88, 202-214. [CrossRef]

31. Al-Emran, M.; Mezhuyev, V.; Kamaludin, A. Technology acceptance model in M-learning context: A systematic review. Comput. Educ. 2018, 125, 389-412. [CrossRef]

32. Mortenson, M.J.; Vidgen, R. A computational literature review of the technology acceptance model. Int. J. Inf. Manag. 2016, 36, 1248-1259. [CrossRef]

33. Wan-Yu, C.; I-Ying, C. An investigation of students' motivation to learn and learning attitude affect the learning effect: A case study on tourism management students. Anthropologist 2013, 16, 457-463.

34. Huang, F. Effects of the application of STEAM education on students' learning attitude and outcome-The case of Fujian Chuanzheng communications college. Rev. Cercetare Interv. Soc. 2020, 69, 349-356. [CrossRef] 
35. Liao, C.-W.; Cheng, P.-W. Longitudinal study of economically disadvantaged Student's learning attitude and academic performance. J. Educ. Pract. Res. 2019, 32, 71-105.

36. Hwang, G.-J.; Chang, H. A formative assessment-based mobile learning approach to improving the learning attitudes and achievements of students. Comput. Educ. 2011, 56, 1023-1031. [CrossRef]

37. Shaw, G.; Marlow, N. The role of student learning styles, gender, attitudes and perceptions on information and communication technology assisted learning. Comput. Educ. 1999, 33, 223-234. [CrossRef]

38. Shih, J.L.; Chu, H.C.; Hwang, G.J.; Kinshuk. An investigation of attitudes of students and teachers about participating in a context-aware ubiquitous learning activity. Br. J. Educ. Technol. 2011, 42, 373-394. [CrossRef]

39. Hwang, G.-J.; Yang, L.-H.; Wang, S.Y. A concept map-embedded educational computer game for improving students' learning performance in natural science courses. Comput. Educ. 2013, 69, 121-130. [CrossRef]

40. Weisell, R.C. Body mass index as an indicator of obesity. Asia Pac. J. Clin. Nutr. 2002, 11, S681-S684. [CrossRef]

41. Tolmie, A.K.; Topping, K.J.; Christie, D.; Donaldson, C.; Howe, C.; Jessiman, E.; Livingston, K.; Thurston, A. Social effects of collaborative learning in primary schools. Learn. Instruction 2010, 20, 177-191. [CrossRef]

42. Chen, S.Y.; Chang, L.-P. The influences of cognitive styles on individual learning and collaborative learning. Innov. Educ. Teach. Int. 2016, 53, 458-471. [CrossRef]

43. Dillenbourg, P. What do you mean by collaborative learning? In Collaborative-Learning: Cognitive and Computational Approaches; Elsevier: Oxford, UK, 1999; pp. 1-19.

44. Fawcett, L.M.; Garton, A.F. The effect of peer collaboration on children's problem-solving ability. Br. J. Educ. Psychol. 2005, 75, 157-169. [CrossRef]

45. Johnson, D.W.; Johnson, R.T.; Buckman, L.A.; Richards, P.S. The effect of prolonged implementation of cooperative learning on social support within the classroom. J. Psychol. 1985, 119, 405-411. [CrossRef]

46. Marzano, R.J.; Pickering, D.J.; Pollock, J.E. Classroom Instruction That Works. Research-Based Strategies for Increasing Student Achievement; Pearson: London, UK, 2004.

47. Slavin, R.E. Are cooperative learning and untracking harmful to the gifted? Educ. Leadersh. 1991, 48, 68-71.

48. Good, T.L.; Mulryan, C.M.; Mccaslin, M.M. Grouping for instruction in mathematics: A call for programmatic research on small-group processes. In Handbook of Research on Mathematics Teaching and Learning: A Project of the National Council of Teachers of Mathematics; Macmillan Publishing Co, Inc.: New York, NY, USA, 1992; pp. 165-196.

49. Keeler, C.M.; Steinhorst, R.K. Using small groups to promote active learning in the introductory statistics course: A report from the field. J. Stat. Educ. 1995, 3. [CrossRef]

50. Loes, C.N.; An, B.P.; Saichaie, K.; Pascarella, E.T. Does collaborative learning influence persistence to the second year of college? J. Higher Educ. 2017, 88, 62-84. [CrossRef]

51. Serrano-Cámara, L.M.; Paredes-Velasco, M.; Alcover, C.; Velazquez-Iturbide, J.Á. An evaluation of students' motivation in computer-supported collaborative learning of programming concepts. Comput. Hum. Behav. 2014, 31, 499-508. [CrossRef]

52. Greene, A.; O'Neil, K.; Lhotksy, G. Exploring a new division 1 football program on a university campus: An application of collaborative action research in higher education. J. Work-Appl. Manag. 2017, 9, 5-17. [CrossRef]

53. Bradbury-Huang, H. What is good action research? Why the resurgent interest? Action Res. 2010, 8, 93-109. [CrossRef]

54. Stringer, E.T. Action Research; Sage Publications, Inc.: Los Angeles, CA, USA, 2007.

55. Ministry of Health and Welfare. Regulations for Organization and Operation of Human Research Ethics Review Board. 2012; MOHW. Available online: https:/ / dep.mohw.gov.tw/doma/dl-16078-31bb0e95-2407-4323-9bbf-a62b7f8dcee3.html (accessed on 5 July 2012).

56. Paige, J.B.; Daley, B.J. Situated cognition: A learning framework to support and guide high-fidelity simulation. Clin. Simul. Nurs. 2009, 5, e97-e103. [CrossRef]

57. Chen, Y.S.; Kao, T.-C.; Sheu, J.-P. A mobile learning system for scaffolding bird watching learning. J. Comput. Assist. Learn. 2003, 19, 347-359. [CrossRef]

58. Mahajan, R.; Sodhi, J.S.; Mahajan, V. Usage patterns discovery from a web log in an Indian e-learning site: A case study. Educ. Inf. Technol. 2016, 21, 123-148. [CrossRef]

59. Hou, H.-Y.; Agrawal, S.; Lee, C.-F. Computational thinking training with technology for non-information undergraduates. Thinking Skills Creativity 2020, 38, 100720. [CrossRef]

60. Hou, H.-Y.; Agrawal, S.; Lo, Y.-L.; Lee, C.-F. Applying Talent Quality-management System (TTQS) and information visualization to e-learning partner project. Adv. Intell. Syst. Comput. 2020, 1145, 207-217. [CrossRef]

61. Wang, Y.H.; Huang, C.I.; Chu, B.; Lee, L.S. Before and after comparison of the employee perception using TTQS-A case study of a hospital in Taipei. Qual. Mag. 2012, 48, 25-30.

62. Hornby, G. The effectiveness of cooperative learning with trainee teachers. J. Educ. Teach. 2009, 35, 161-168. [CrossRef]

63. NTCNC. Educational Objectives of Department of Nursing [Online]. 2009. NTCNC. Available online: http:/ / www.ntcnc.edu. tw / onweb.jsp?webno=3333332633 (accessed on 20 February 2011).

64. Grant, M.S.; Jenkins, L.S. Communication education for pre-licensure nursing students: Literature review 2002-2013. Nurse Educ. Today 2014, 34, 1375-1381. [CrossRef]

65. Lai, C. Training nursing students' communication skills with online video peer assessment. Comput. Educ. 2016, 97, 21-30. [CrossRef] 
66. Lin, K.-Y.; Shen, Y.F. The nursing students' attitude toward using blogs in a nursing clinical practicum in Taiwan: A 3-R framework. Nurse Educ. Today 2013, 33, 1079-1082. [CrossRef]

67. Conrad, J.; Nöthlings, U. Innovative approaches to estimate individual usual dietary intake in large-scale epidemiological studies. Proc. Nutr. Soc. 2017, 76, 213-219. [CrossRef]

68. Spinuzzi, C. The methodology of participatory design. Tech. Commun. 2005, 52, 163-174.

69. Wang, S.; Huang, W.; Peng, L.; Pan, D.; Huang, N.; Hu, J.; Peng, Y. Smart skin flap postsurgical pre-warning mobile app design. In Advances in Intelligent Systems and Computing, Proceedings of the International Conference on Applied Human Factors and Ergonomics-Advances in Human Factors and Ergonomics in Healthcare and Medical Devices, Orlando, FL, USA, 21-25 July 2018; Springer: Cham, Switzerland, 2018; pp. 119-129. [CrossRef] 